\title{
Solid Matrix Priming with Hydrogels on Heteropappus arenarius Seeds
}

\author{
Chang Hee Lee* \\ ${ }^{I}$ Department of Horticulture, Hankyong National University, Anseong 456-749, Korea \\ ${ }^{2}$ Research Institute of International Agriculture, Technology, and Information, Hankyong National University, \\ Anseong 456-749, Korea
}

\begin{abstract}
This study was initiated to evaluate hydrophilic polymers (hydrogels) as a new solid matrix medium for seed-priming of Heteropappus arenarius Kitam. Solid matrix priming (SMP)-media were prepared with the combination of $\mathrm{Na}$ - and K-based hydrogels and hydrogels with three different dry levels (DC; 70\%, $80 \%$, and $90 \%$ ). Priming was performed in the dark at 15 or $20^{\circ} \mathrm{C}$ for 24 hours, and all primed seeds were incubated at $20^{\circ} \mathrm{C}$ in the dark for the germination test. Non-primed seeds and seeds primed with distilled water (DW) were also included. To reach the germination rate of 50\% $\left(\mathrm{T}_{50}\right)$, it took 4.0 days for non-primed seeds, and 3.6 and 3.9 days for DW-primed seeds at 15 and $20^{\circ} \mathrm{C}$, respectively. Na-based hydrogel-primed seeds with 70\% DC ( $\mathrm{Na} 70 \%$ ) showed the fastest germination, which respectively took and 1.9 and 1.8 days at 15 and $20^{\circ} \mathrm{C}$ to $\mathrm{T}_{50}$. K-based hydrogel-primed seeds with $70 \% \mathrm{DC}$ showed the fastest germination among K-based hydrogels with various DC levels, but it took 0.6 days more to $\mathrm{T}_{50}$ compared to $\mathrm{Na} 70 \%$. The hydration rate (HR) of DW-primed seeds was $37 \%$ lower than that of $\mathrm{Na} 70 \%$-primed seeds at $15^{\circ} \mathrm{C}$ priming temperature, which indicates that $\mathrm{Na} 70 \%$ priming is the best solid matrix priming condition for promoting the germination of $H$. arenarius seeds.
\end{abstract}

Additional key words: hydration rate, K-based hydrogel, Na-based hydrogel, seed priming

\section{Introduction}

Heteropappus arenarius Kitam., a wild autumn-flowering biennial belonging to the family Asteraceae, is native over the ranges in the southern coastal area of Korean Peninsula and Jeju Island. It has been widely used as a ground cover plant over a large-scale landscape, especially on barren soil or hillsides planted by using hydro-seeding technique (Lee, 2004). Lee and Nam (2009) reported that an optimum germination temperature and harvesting stage influenced by local strains of $H$. arenarius, but no seed-priming studies on this species have been reported. Priming improves seed germination, resulting in rapid and more synchronous seedling emergence under low temperatures on various vegetables, such as Asparagus officinalis L. (Bittencourt et al., 2004), Brassica spp. (Zheng et al., 1994), Capsicum anmuum L. (Kang et al., 1997), Eschscholzia californica (Lee et al., 2010), Gymnaster koraiensis (Kim et al., 2009) and Lycopersicon esculentum Mill. (Arin and
Kiyak, 2003). Taylor et al. (1988) developed solid matrix priming (SMP) technique and evaluated its ability to improve seedling establishment of small-seeded vegetable crops such as tomato, carrot, and onion under either sub- or supra-optimal temperatures. The seedling emergence characteristics of SMP seeds were greater than, or equal to those of the conventional solution priming techniques using $\mathrm{KNO}_{3}$ or PEG. Purple coneflower seeds [Echinacea purpurea (L.) Moench] with matrix priming in vermiculite showed the greater germination rate, and synchrony than those of non-primed seeds. Emergence was faster from the primed than from non-primed seeds in both cool $\left(23-27^{\circ} \mathrm{C}\right)$ and warm $\left(35-40^{\circ} \mathrm{C}\right)$ temperature regimes (Pill et al., 1994). Hardegree and Emmerich (1992) also investigated the effect of matrix-priming duration and priming water potential on the germination response of Bouteloua curtipendula (Michx.) Torr., Cenchrus ciliaris L., Eragrostis lehmanniana Nees, and Panicum coloratum L.

The polymers are characterized as either hydrophilic or

\footnotetext{
*Corresponding author: changheelee@hknu.ac.kr

※ Received 3 July 2013; Revised 2 August 2013; Accepted 13 August 2013. This study was carried out with the support of "Cooperative Research Program for Agricultural Science \& Technology Development (Project No. PJ008495022013)”, Rural Development Adminstration, Republic of Korea.

(c) 2013 Korean Society for Horticultural Science
} 
hydrophobic. Hydrophilic polymers ("hydrogels"), long-chain, cross-linked organic molecules, have been used in the nursery and floriculture industries to enhance water uptake (Gehring and Lewis, 1980; Schneider and Renault, 1997; Still, 1976) and to improve the water-holding capacity of growth media (Blodgett et al., 1993). These hydrogels, when incorporated into potting media, could absorb water 400-600 times of their weight and this stored water was released as required by the plant (Lamont and O'Connell, 1987). To determine the use of polymers as a seed-coating treatment, Kavak and Eser (2009) assessed the effects of a number of polymers on water uptake during seed imbibition before and after a period of storage; however, SMP using hydrogels has not been reported even though these polymers have excellent water holding ability. Thus, this study was initiated to evaluate hydrogels as a new media for the SMP of $H$. arenarius seeds.

\section{Materials and Methods}

\section{Plant Materials}

Seeds of H. arenarius Kitam. (Asteraceae) were collected from the natural habitat of Guryongpo-eup, Pohang-si, Gyeongsangbuk-do in November, 2010 and then stored in a humidity-control cabinet (AH-80, Patron, Taiwan) at ambient temperature and $20 \%$ relative humidity $(\mathrm{RH})$ until needed. All seeds were selected by hand for size uniformity (length $\times$ width: $3.4 \pm 0.4 \times 2.4 \pm 0.4 \mathrm{~mm}$ ), sterilized with sodium hypochlorite (1\%) for $10 \mathrm{~min}$, and rinsed three times with distilled water (DW) before SMP treatments.

\section{Preparation of Hydrogels for SMP}

Hydrogels (Hi-swell series; Songwon Industrial Co., Ltd., Ulsan, Korea) used in this experiment were divided into Na-based hydrogel (sodium polyacrylate) and K-based hydrogel (potassium polyacrylate) according to core ion. The grains of each hydrogel were between 1.0 to $2.0 \mathrm{~mm}$ in diameter after sorted by testing sieves (Chunggye Sanggong Sa, Seoul, Korea). About $0.1 \mathrm{~g}$ of grains was taken from each hydrogel and hydrated for $24 \mathrm{~h}$ in $150 \mathrm{~mL}$ of $\mathrm{DW}$ to reach the full hydration rate (HR) at 15 and $20^{\circ} \mathrm{C}$ in the dark, respectively. Dry content (DC, \%) of each hydrated hydrogel was controlled by halogen moisture analyzer (HB43-S; Mettler Toledo, Zurich, Switzerland) adjusted to $80^{\circ} \mathrm{C}$ until desired dry content (DC, $\%)$ reached before beginning SMP. The DC levels of the hydrated hydrogel were set to $70 \%, 80 \%$, and $90 \%$.

\section{SMP Treatments}

SMP media with Na-based or K-based hydrogel were prepared, which had been hydrated to $70 \%, 80 \%$, and $90 \%$ $\mathrm{DC}$, and put at 15 or $20^{\circ} \mathrm{C}$ priming temperatures (2 SMP media $\times 3$ DC levels $\times 2$ priming temperatures). DW-primed seeds were also put at 15 or $20^{\circ} \mathrm{C}$ priming temperatures. $H$. arenarius seeds were primed in each treatment under dark condition for $24 \mathrm{~h}$ and then separated from each medium. The moisture from seed surfaces was removed using paper towel. Non-primed seeds were included as a control.

The abbreviations for each treatment are as follows: DWprimed seeds at $15^{\circ} \mathrm{C}$ priming temperature were DW-15; At $15^{\circ} \mathrm{C}$ priming temperature, Na-based hydrogel-primed seeds with $70 \%, 80 \%$, and $90 \%$ DC were $\mathrm{Na} 70 \%-15$, Na $80 \%-15$, and $\mathrm{Na} 90 \%-15$, respectively; At $15^{\circ} \mathrm{C}$ priming temperature, K-based hydrogel-primed seeds with $70 \%, 80 \%$, and $90 \%$ DC were K $70 \%-15$, K $80 \%-15$, and K $90 \%-15$, respectively; DW-primed seeds at $20^{\circ} \mathrm{C}$ priming temperature were DW-20; At $20^{\circ} \mathrm{C}$ priming temperature, Na-based hydrogelprimed seeds with $70 \%, 80 \%$, and $90 \%$ DC were $\mathrm{Na} 70 \%-20$, $\mathrm{Na} 80 \%-20$, and $\mathrm{Na} 90 \%-20$, respectively; At $20^{\circ} \mathrm{C}$ priming temperature, K-based hydrogel-primed seeds with $70 \%, 80 \%$, and $90 \%$ DC were $\mathrm{K} 70 \%-20$, K $80 \%-20$, and $\mathrm{K} 90 \%-20$, respectively.

\section{Germination Assay}

The assay was performed with four replications of 50 seeds in 9-cm Petri dishes containing two layers of filter paper (Whatman No. 2); the seeds in each Petri dish were moistened with $5 \mathrm{~mL}$ deionized DW. Seeds were germinated in multi-room incubator (VS-3DM; Vision Scientific Co., Ltd., Korea) at the optimum germination temperature of $H$. arenarius seeds $\left(20^{\circ} \mathrm{C}\right.$; Lee and Nam, 2009) under the dark condition. A seed was regarded as germinated when the radicles protruded through the seed coat $(>2 \mathrm{~mm})$. Germinated seeds were counted daily and then removed immediately to prevent counting error. Final germination percentage (FGP) was investigated 10 days after sowing, and the days to $25 \%$ and $50 \%$ germination $\left(\mathrm{T}_{20}\right.$ and $\left.\mathrm{T}_{50}\right)$ were calculated from sigmoid regression curves at each seed-germination treatment using SigmaPlot (Ver. 10.0, Systat Software, Inc., Chicago, Illinois, USA). The germination data collected were analyzed using SAS (V9.1, Cary, North Carolina, USA) under a completely randomized block design and the means were compared by Duncan's multiple range test at $5 \%$.

\section{Comparison of Seed Dry Contents between Primed and Non-primed Seeds}

The seed dry contents between SMP seeds and DW-primed seeds were compared to determine how the primed seeds would absorb moisture. $H$. arenarius seeds $(0.5 \mathrm{~g})$ were primed with either DW-15 or Na $70 \%-15$ under dark condition for $24 \mathrm{~h}$ and then the moisture from seed surfaces was removed. Na $70 \%-15$ treatment was included to reveal the 
reason why the treatment showed the best germination speed $\left(\mathrm{T}_{50}\right)$ among all SMP treatments, which was based on the following results of the effects of SMPs in this study. The initial weight of DW-15 seeds was referred to as $100 \% \mathrm{DC}$ (seeds saturated with DW) and the initial weight of $\mathrm{Na}$ $70 \%-15$ seeds was calculated as the relative percentage compared with the initial weight of DW-15 seeds. The percentage of change in DC was measured using halogen moisture analyzer (HB43-S; Mettler Toledo, Zurich, Switzerland) at $50^{\circ} \mathrm{C}$ for $140 \mathrm{~min}$.

\section{Results and Discussion}

\section{Hydration and Temperature Characteristics of Hydrogels}

Hydrogels showed various water absorption rates according to temperature and base ion (Table 1). Na-based hydrogel swelled to $320-332 \%$ of its initial weight over $24 \mathrm{~h}$, but K-based hydrogel swelled to only $220-233 \%$. Shim et al. (2008) investigated the HRs of Na-based hydrogels (2-4 mm) and K-based hydrogels (2-3 mm) such as those used in this experiment (Hi-swell series; Songwon Industrial Co., Ltd., Ulsan, Korea). The larger grains had higher HRs. The HR of Na-based hydrogel was $>450 \%$; that of K-based hydrogel was about $300 \%$. The results from both this and the previous studies (Shim et al., 2008) indicate that the water uptake of Na-based hydrogel is superior to that of K-based hydrogel.

Shim et al. (2008) also reported that the small, medium, and large K-SAM series polymers (Kolon Chemical Co., Ltd., Ulsan, Korea) had lower HRs compared to that of the Hi-swell series and showed no difference according to particle sizes in DW. Such polymers differed from each other in the specific monomer building block, amount of water absorbed per gram of material, particle size and distribution, response to salinity, and cost (Johnson and Veltkamp, 1985). In addition, several manufacturers substitute $\mathrm{K}$ for $\mathrm{Na}$ in their products because of its reduced toxicity to plants (Orzolek, 1993). As the concentration of ions increases in water, the amount of polymer hydration decreases (Evans et al., 1990). The degree of reduced water-holding capacity of a particular hydrogel depends on the structure and chemical composition of the product and the concentration and variety of ions in the water to which the hydrogel is exposed (James and Richards, 1986; Wang, 1987).

The time approaching the target \% DC in the Na-based hydrogel was delayed compared to that in the K-based hydrogel (Fig. 1). Although the hydration of K-based hydrogel at $20^{\circ} \mathrm{C}$ decreased faster than that at $15^{\circ} \mathrm{C}$, the hydration temperature did not affect the water content within the same polymer (Table 1).

\section{Comparing Effects Two Typed of Hydrogels on Seed Germination}

Non-primed seeds, DW-20, and DW-15 were the last group to reach out at $25 \%$ seed germination $\left(\mathrm{T}_{25}\right)$, immediately preceded by K 70\%-15, Na 90\%-15, K 90\%-20, K 90\%-15, $\mathrm{Na} 90 \%-20$, and $\mathrm{K} 80 \%-20$, and then by $\mathrm{Na} 80 \%-15$, Na 80\%-20, and K 80\%-15 (Table 2). K 70\%-20, Na 70\%-15, and $\mathrm{Na} 70 \%-20$ were included to the fastest. To reach out at $50 \%$ seed germination $\left(\mathrm{T}_{50}\right)$, non-primed seeds, DW-20,

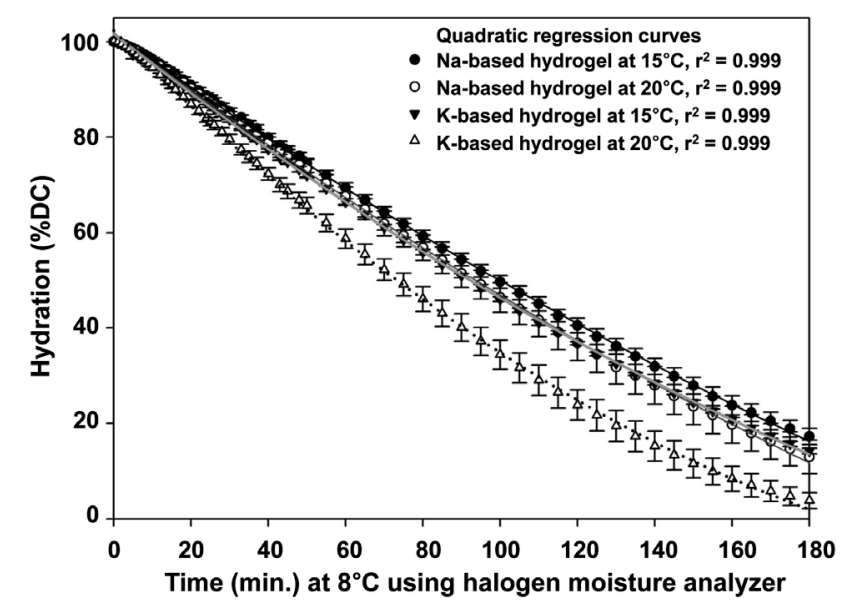

Fig. 1. Changes of hydration rates (dry content [DC], \%) on two types of hydrogels depending on priming temperature.

Table 1. Characteristics of hydrogels depending on hydration (\% dry content [DC]) and temperature.

\begin{tabular}{|c|c|c|c|c|c|c|}
\hline \multirow{2}{*}{$\begin{array}{l}\text { Solid matrix priming } \\
(\mathrm{SMP}) \text { sources }^{\mathrm{z}}\end{array}$} & \multirow{2}{*}{$\begin{array}{c}\text { Hydration } \\
\text { temperature }\left({ }^{\circ} \mathrm{C}\right)\end{array}$} & \multirow{2}{*}{$\begin{array}{l}\text { Initial weight } \\
\text { before hydration }(\mathrm{g})\end{array}$} & \multirow{2}{*}{$\begin{array}{c}\text { Weight after } \\
\text { hydration for } 24 \mathrm{~h}(\mathrm{~g})\end{array}$} & \multicolumn{3}{|c|}{ Weight approaching target \% DC $(\mathrm{g})^{y}$} \\
\hline & & & & $90 \%$ & $80 \%$ & $70 \%$ \\
\hline \multirow[t]{2}{*}{ Na-based hydrogel } & 15 & 0.1 & $33.2 \mathrm{a}^{\mathrm{x}}$ & 29.9 a & $26.5 \mathrm{a}$ & $23.2 \mathrm{a}$ \\
\hline & 20 & 0.1 & $32.0 \mathrm{a}$ & 28.8 a & 25.6 a & $22.4 \mathrm{a}$ \\
\hline \multirow[t]{2}{*}{ K-based hydrogel } & 15 & 0.1 & $23.3 \mathrm{~b}$ & $20.9 b$ & $18.6 \mathrm{~b}$ & $16.3 \mathrm{~b}$ \\
\hline & 20 & 0.1 & $22.0 \mathrm{~b}$ & $19.8 b$ & $17.6 \mathrm{~b}$ & $15.4 \mathrm{~b}$ \\
\hline
\end{tabular}

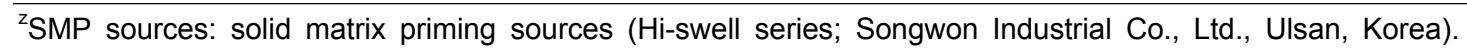

${ }^{y}$ Level of DC (\%) within each polymer was controlled by the halogen moisture analyzer adjusted to $80^{\circ} \mathrm{C}$ and weight approaching target \% DC was derived from each quadratic regression curve in Fig. 1.

${ }^{x}$ Mean separation within columns using Duncan's multiple range test, $5 \%$ level. 
and DW-15 were the latest, preceded by $\mathrm{K} 70 \%-15$, Na 90\%-15, K 90\%-20, K 90-15, and $\mathrm{Na} 90 \%-20$, and then by $\mathrm{Na} 80 \%-20, \mathrm{~K} 80 \%-15, \mathrm{~K} 80 \%-20, \mathrm{Na} 80 \%-15$, and $\mathrm{K} 70 \%-20$. $\mathrm{Na} 70 \%-15$ and $\mathrm{Na} 70 \%-20$ were included to the fastest.

Non-primed seeds took 4.0 days to $\mathrm{T}_{50}$ and DW-15 and DW-20 took 3.6 and 3.9 days to $\mathrm{T}_{50}$, respectively. Most seeds primed with the two hydrogels showed faster seed germination compared to non-primed seeds and DW-primed seeds. $\mathrm{Na} 70 \%$ showed the fastest seed germination among all treatments: $\mathrm{Na} 70 \%-15$ took 1.4 to $\mathrm{T}_{25}$ and 1.9 days to $\mathrm{T}_{50} ; \mathrm{Na} 70 \%-20$ took 1.2 to $\mathrm{T}_{25}$ and 1.8 days to $\mathrm{T}_{50}$. K 70\%-20 showed the fastest seed germination among the K-based hydrogels with various DCs, but its $\mathrm{T}_{50}$ was delayed by 0.6 days compared to that of $\mathrm{Na} 70 \%-20$. Moreover, the $\mathrm{T}_{50}$ of $\mathrm{Na} 70 \%-20$ was 2.1 days shorter than that of DW-20.

Table 2. $T_{25}, T_{50}$, and final germination percentage (FGP) of $H$. arenarius seeds as influenced by solid matrix priming (SMP) treatments using two types of hydrogels.

\begin{tabular}{|c|c|c|c|c|}
\hline $\mathrm{SMP}^{\mathrm{z}}$ & DC $\%^{y}$ & $\mathrm{~T}_{25}$ & $\mathrm{~T}_{50}$ & FGP (\%) \\
\hline Non-primed & & $3.2 \mathrm{a}^{\mathrm{x}}$ & $4.0 \mathrm{a}$ & $72.5 \mathrm{a}$ \\
\hline \multicolumn{5}{|c|}{ Priming temperature at $15^{\circ} \mathrm{C}$} \\
\hline DW & & $2.9 \mathrm{ab}$ & $3.6 \mathrm{abc}$ & 75.5 a \\
\hline \multicolumn{5}{|c|}{ Na-based hydrogel } \\
\hline & 90 & $2.5 \mathrm{c}$ & $3.4 \mathrm{abcd}$ & $77.0 \mathrm{a}$ \\
\hline & 80 & $1.8 \mathrm{e}$ & 2.5 ef & 80.5 a \\
\hline & 70 & $1.4 \mathrm{f}$ & $1.9 \mathrm{~g}$ & 85.5 a \\
\hline \multicolumn{5}{|c|}{ K-based hydrogel } \\
\hline & 90 & $2.3 \mathrm{~cd}$ & $3.3 \mathrm{bcd}$ & 77.0 a \\
\hline & 80 & $1.8 \mathrm{e}$ & 2.8 def & $71.0 \mathrm{a}$ \\
\hline & 70 & $2.6 \mathrm{bc}$ & $3.6 \mathrm{abc}$ & $86.0 \mathrm{a}$ \\
\hline \multicolumn{5}{|c|}{ Priming temperature at $20^{\circ} \mathrm{C}$} \\
\hline DW & & $3.2 \mathrm{a}$ & $3.9 \mathrm{ab}$ & $76.0 \mathrm{a}$ \\
\hline \multicolumn{5}{|c|}{ Na-based hydrogel } \\
\hline & 90 & $2.0 \mathrm{de}$ & 3.0 cde & $75.0 \mathrm{a}$ \\
\hline & 80 & $1.8 \mathrm{e}$ & 2.9 def & $77.5 \mathrm{a}$ \\
\hline & 70 & $1.2 \mathrm{f}$ & $1.8 \mathrm{~g}$ & $76.5 \mathrm{a}$ \\
\hline \multicolumn{5}{|c|}{ K-based hydrogel } \\
\hline & 90 & $2.4 \mathrm{~cd}$ & $3.3 \mathrm{abcd}$ & $73.5 \mathrm{a}$ \\
\hline & 80 & $2.0 \mathrm{de}$ & 2.7 ef & 77.3 a \\
\hline & 70 & $1.4 \mathrm{f}$ & $2.4 \mathrm{fg}$ & $68.5 \mathrm{a}$ \\
\hline Significance & & $* * *$ & $* * *$ & ns \\
\hline
\end{tabular}

${ }^{z}$ SMP sources: solid matrix priming sources (Hi-swell series; Songwon Industrial Co., Ltd., Ulsan, Korea); Na-based hydrogel: sodium polyacrylate; K-based hydrogel: potassium polyacrylate. 'Level of dry content (DC, \%) within each hydrogel was controlled by the halogen moisture analyzer adjusted to $80^{\circ} \mathrm{C}$.

×Mean separation within columns using Duncan's multiple range test, $5 \%$ level.

${ }_{\mathrm{ns},{ }^{* \star *}}$ Non-significant or significant at $P=0.001$, respectively.
Considering that the germination of $H$. arenarius seed generally requires approximately 1 week after sowing, SMP using Na-based hydrogels with $70 \% \mathrm{DC}$ is expected to be the best condition for germination speed among all treatments. There was, nevertheless, no significant difference in FGP (\%) observed in all treatments, including non-primed seeds, DW, or SMPs (Table 2). However, K 70\%-20 showed unexpected $\mathrm{T}_{25}$ and $\mathrm{T}_{50}$ values, when compared to the germination patterns of other treatments. It is presumed to be derived from experimental error; as a consequence of incorrect seed germination counting from the early stage to the middle.

The one-way effects of each factor such as hydrogel type, priming temperature, $\mathrm{DC}$ at $\mathrm{T}_{25}$ and $\mathrm{T}_{50}$, and FGP were shown in Table 3. The significant difference at $\mathrm{T}_{50}$ was found between Na-based and K-based hydrogel ( $P \leq 0.05)$, and it was that Na-based hydrogel-primed seeds showed faster germination than the other. Comparing water uptake characteristics between Na-based and K-based hydrogel in this study and the previous study (Shim et al., 2008), the former was found to be superior to the latter. Recalculating the amount of water absorption, the Na-based hydrogel with $70 \%$ DC corresponds to uptake $228 \%$ of water based on the weight of hydrogel itself, but the K-based hydrogel with $70 \%$ DC corresponds to uptake $160 \%$ of water based on its weight. Therefore, the higher

Table 3. $T_{25}, T_{50}$, and final germination percentage (FGP) of $H$. arenarius seeds as influenced by major factors such as hydrogel type, priming temperature, and dry content (DC) of each hydrogel.

\begin{tabular}{|c|c|c|c|}
\hline Comparison of factors ${ }^{z}$ & $\mathrm{~T}_{25}$ & $\mathrm{~T}_{50}$ & FGP (\%) \\
\hline \multicolumn{4}{|c|}{ Hydrogel } \\
\hline $\mathrm{Na}$ & $1.8 \mathrm{a}^{\mathrm{y}}$ & $2.6 \mathrm{~b}$ & 78.7 a \\
\hline $\mathrm{K}$ & $2.1 \mathrm{a}$ & $3.0 \mathrm{a}$ & $75.5 \mathrm{a}$ \\
\hline Significance & ns & * & ns \\
\hline \multicolumn{4}{|c|}{ Priming temperature } \\
\hline $15^{\circ} \mathrm{C}$ & $2.1 \mathrm{a}$ & $2.9 \mathrm{a}$ & 79.5 a \\
\hline $20^{\circ} \mathrm{C}$ & $1.8 \mathrm{a}$ & $2.7 \mathrm{a}$ & 74.6 b \\
\hline Significance & ns & ns & * \\
\hline \multicolumn{4}{|c|}{ DC of hydrogel } \\
\hline $90 \%$ & $2.3 \mathrm{a}$ & $3.3 \mathrm{a}$ & 75.6 a \\
\hline $80 \%$ & $1.9 \mathrm{~b}$ & $2.8 \mathrm{~b}$ & $76.5 \mathrm{a}$ \\
\hline $70 \%$ & $1.6 \mathrm{~b}$ & $2.4 \mathrm{~b}$ & $79.1 \mathrm{a}$ \\
\hline Significance & $* * *$ & $* \star *$ & ns \\
\hline
\end{tabular}

${ }^{\mathrm{z}}$ Comparing between two hydrogels, non-primed seeds and DW-primed seeds were excluded; comparing between two priming temperatures, non-primed seeds were excluded; comparing among DC level hydrogel, non-primed seeds and DW-primed seeds were excluded.

${ }^{y}$ Mean separation within columns of each factor using Duncan's multiple range test, $5 \%$ level.

ns,, Non-significant or significant at $P=0.05$ or 0.001 , respectively. 
water content of $\mathrm{Na} 70 \%$ is expected to induce more water absorption of primed seeds compared to that of $\mathrm{K} 70 \%$. However, there was no significant difference between the two type hydrogel-primed seeds on $\mathrm{T}_{25}$ and FGP. Seeds primed at $20^{\circ} \mathrm{C}$ tended to germinate slightly faster than those primed at $15^{\circ} \mathrm{C}$. While priming temperature on $\mathrm{T}_{25}$ and $\mathrm{T}_{50}$ showed no significant effect, it had a significant influence on FGP ( $P \leq 0.05)$ : seeds primed at $15^{\circ} \mathrm{C}$ showed a higher FGP than those primed at $20^{\circ} \mathrm{C}$. Many researchers have suggested that the optimum priming temperature for seed germination is from 15 to $20^{\circ} \mathrm{C}$ : Kim et al. (2009) reported that the FGP of Aster koraiensis seeds primed at $15^{\circ} \mathrm{C}$ dramatically increased from $32 \%$ (control) to $83 \%$, and was higher than that of seeds primed at $30^{\circ} \mathrm{C}(43 \%)$; Lee et al. (2010) also suggested that the proper priming conditions in California poppy seeds was $10^{\circ} \mathrm{C}$ with $100 \mathrm{mM} \mathrm{KNO}$ for $24 \mathrm{~h}$; Shim et al. (2009) reported that the increase of priming temperature from 15 to $30^{\circ} \mathrm{C}$ was associated with significant decrease in the germination percentage of sesame seeds and $15^{\circ} \mathrm{C}$ priming temperature resulted in the fastest germination rate and highest germination percentage.

Among the DC treatments of hydrogel, there was a very significant difference on $\mathrm{T}_{25}(P \leq 0.001)$ and $\mathrm{T}_{50}(P \leq$ 0.001 ), regardless of the hydrogel type (Table 3$) .70 \% \mathrm{DC}$ significantly promoted the seed germination compared to the others and showed the fastest germination (2.4 days), followed by $80 \%$ (2.8 days) and $90 \%$ (3.3 days) at $\mathrm{T}_{50}$. The average $\mathrm{T}_{50}$ on $70 \%$ DC, except for data on $\mathrm{K} 70 \%-20$, was recalculated as 2.0 days (data were not shown), which was 1.3 and 2.0 days faster than that of $90 \% \mathrm{DC}$ and non-primed seeds, respectively. The graphic data depicted in Fig. 2 shows the linear regression curves on the correlation between $\mathrm{T}_{50}$ and the water uptake of each polymer based on Table 1. Each

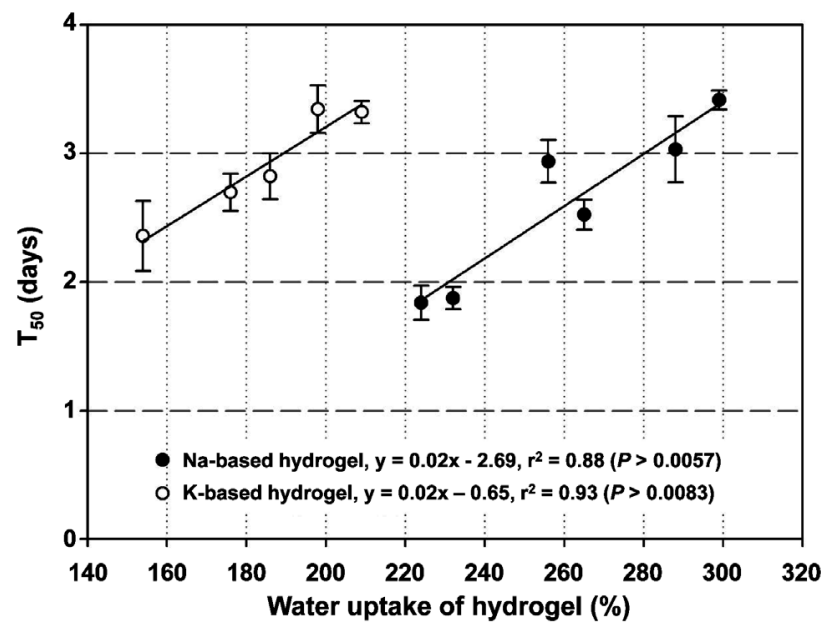

Fig. 2. Linear regressions between $T_{50}$ of SMP-H. arenarius seeds and water uptake (\%) absorbed by $\mathrm{Na}$-based and K-based hydrogels.
$\mathrm{T}_{50}$ of SMP-seeds was higher in proportion to the water uptake rates of $\mathrm{Na}$-based and $\mathrm{K}$-based hydrogels, but the increasing pattern on $\mathrm{T}_{50}$ varied depending on hydrogel type. In other words, the ability to draw water depending on hydrogel type had a larger impact on seed germination than the specific amount of water absorbed by hydrogel.

\section{Comparison of Seed Dry Contents between Primed and Non-primed Seeds}

The hydration rate (HR) of DW-primed seeds was $37 \%$ lower than that of $\mathrm{Na} 70 \%$-primed seeds at $15^{\circ} \mathrm{C}$ priming temperature under the full hydration (Fig. 3). Although HR decreased in proportion to the drying process, the HR difference between DW and Na 70\%-15 was approximately 45\% after $1 \mathrm{~h}$ and then finally became to $19 \%$ when the moisture content of the seed no longer deceased. SMP was a process by which seeds are mixed with a solid material and water in known proportions. This mixture allowed the seeds to absorb and attain threshold moisture content, but prevented emergence of the radicle. Taylor et al. (1988) reported that the ground Leonardite Shale (Agro-Lig), known as a SMP material, which was a friable material and had a high waterholding capacity, decreased the time for $50 \%$ seedling emergence and increased the plant dry weight compared with the nontreated controls for each crop. Hardegree and Emmerich (1992) reported that optimum germination generally occurred in the priming condition for high water potential over the shortest period of time. Kavak and Eser (2009) reported that onion seeds coated with two polymers known to be hydrophilic (Discoshine L-88 blue and carboxymethyl cellulose) absorbed more water than untreated seeds and imbibition was significantly increased, even though coating the seeds with hydrophobic polymers reduced imbibition than the untreated seeds. Therefore, the SMP-seeds using hydrophilic polymer (hydrogel) have

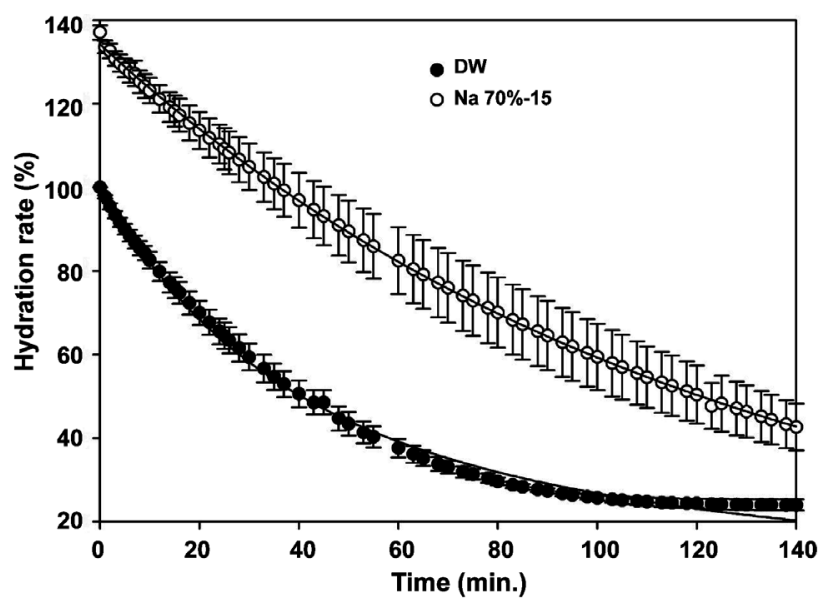

Fig. 3. Hydration rates of $H$. arenarius seeds primed with distilled water (DW) and with Na-based hydrogel with $70 \%$ dry content at $15^{\circ} \mathrm{C}$ priming temperature. 
greater moisture content than DW-primed seeds.

The physical properties of polyacrylamide were extensively characterized; the water-holding capacity was greatly altered in the presence of salts, and, more specifically, salts containing cations such as $\mathrm{Ca}$ and $\mathrm{Mg}$ (Bowman et al., 1990; Foster and Keever, 1990; Johnson, 1984). The substituted strulcture of hydrogels with $\mathrm{K}$ was manufactured to reduce toxicity to plants, but plant growth showed no differences in the treatments with $\mathrm{K}$ polyacrylate polymer compared with other types composed of the $\mathrm{Na}$ polyacrylate polymer (Shim et al., 2008). Starch-based polymers also had many polar hydroxyl groups that made it easier for the polar water molecules to be absorbed into the polymers, resulting in fast water uptake and expansion of the materials (Wang and Gregg, 1990). Shim and Choi (2010) reported that starch polymers absorbed more water than the polyacrylate polymers, and the HR of starch polymers was $65 \%$ higher in DW than in polyacrylate polymers.

In the near future, my research on SMP-seeds would shift toward eco-friendly hydrogels such as natural starch-based hydrogels to be applied to SMP. In conclusion, my result for SMP with hydrogels suggests that this method would be very effective for the seed industry or for the hydro-seeding techniques in plant ecosystem restoration requiring fast seed germination as well as high seed germination.

\section{Literature Cited}

Arin, L. and Y. Kiyak. 2003. The effects of pre-sowing treatments on emergence and seedling growth of tomato seed (Lycopersicon esculentum Mill.) under several stress conditions. Pakistan J. Biol. Sci. 6:990-994.

Bittencourt, M.L.C., D.C.F.S. Dias, L.A.S. Dias, and E.F. Araujo. 2004. Effects of priming on asparagus seed germination and vigour under water and temperature stress. Seed Sci. Technol. 32:607-616.

Blodgett, A.M., D.J. Beattie, J.W. White, and G.E. Elliott. 1993. Hydrophilic polymers and wetting agents affect absorption and evaporative water loss. HortScience 28:633-635.

Bowman, D.C., R.Y. Evans, and J.L. Paul. 1990. Fertilizer salts reduce hydration of polyacrylamide gels and affect physical properties of gel-amended container media. J. Amer. Soc. Hort. Sci. 115:382-386.

Evans, R.Y., I. Sisto, and D.C. Bowman. 1990. The effectiveness of hydrogels in container plant production is reduced by fertilizer salts. Foliage Dig. 3:3-5.

Foster, W.J. and G.J. Keever. 1990. Water absorption of hydrophilic polymers (hydrogel) reduced by media amendments. J. Environ. Hort. 8:113-114.

Gehring, J.M. and J.J. Lewis. 1980. Effect of hydrogel on wilting and moisture stress of bedding plants. J. Amer. Soc. Hort. Sci. 105:511-513.

Hardegree, S.P. and W.E. Emmerich. 1992. Effect of matric-priming duration and primed water potential on germination of four grasses. J. Exp. Bot. 43:233-238.
James, E.A. and D. Richards. 1986. The influences or iron sources on the water holding properties of potting media amended with water absorbing polymers. Sci. Hort. 28:201-208.

Johnson, M.S. 1984. Effect of soluble salts on water absorption by gel-forming soil conditioners. J. Sci. Food. Agr. 35:1063-1066.

Johnson, M.S. and C.J. Veltkamp. 1985. Structure and functioning of water-storing agricultural polyacrylamides. J. Sci. Food. Agr. 36:789-793.

Kang, N.J., Y.O. Jeoung, J.L. Cho, and S.M. Kang. 1997. Changes of seed proteins related to low temperature germinability of primed seeds of pepper (Capsicum annuum L.). J. Kor. Soc. Hort. Sci. 38:342-346.

Kavak, S. and B. Eser. 2009. Influence of polymer coatings on water uptake and germination of onion (Allium cepa L. cv. Aki) seeds before and after storage. Sci. Hort. 121:7-11.

Kim, H.J., H.H. Jung, and K.S. Kim. 2009. Effects of priming on seed germination of Gymnaster koraiensis under low temperature. Kor. J. Hort. Sci. Technol. 27:44-48.

Lamont, G.P. and M.A. O'Conell. 1987. Shelf-life of bedding plants as influenced by potting media and hydrogels. Sci. Hort. 31:141-149.

Lee, C.H. 2004. A taxonomic study on wild chrysanthemum native to Korea. J. Environment-Friendly Agri. Res. 6:159-176.

Lee, C.H., S.Y. Kim, and Y.H. Kim. 2010. Seed priming of the California poppy (Eschscholzia californica). Hort. Environ. Biotechnol. 51:501-506.

Lee, C.H. and K.W. Nam. 2009. Characteristics of seed germination in Heteropappus arenarius Kitam. native to Korea as influenced by temperature. Kor. J. Plant Res. 22:116-122.

Orzolek, M.D. 1993. Use of hydrophilic polymers in horticulture. HortTechnology 3:41-44.

Pill, W.G., C.K. Crossana, J.J. Fretta, and W.G. Smitha. 1994 Matric and osmotic priming of Echinacea purpurea (L.) Moench seeds. Sci. Hort. 59:37-44.

Schneider, A. and P. Renault. 1997. Effects of coating on seed imbibition. I. Model estimates of water transport coefficient. Crop Sci. 37:1841-1849.

Shim, K.B., S.K. Cho, J.D. Hwang, S.B. Pae, M.H. Lee, T.J. Ha, C.H. Park, K.Y. Park, and J.C. Byun. 2009. Effect of seed priming treatment on the germination of sesame. Kor. J. Crop Sci. 54:416-421.

Shim, M.S. and S.Y. Choi. 2010. Growth of Ardisia pusilla as affected by starch or polyacrylate polymer mixed in the media. Hort. Environ. Biotechnol. 51:239-244.

Shim, M.S., S.Y. Choi, and O.K. Kwon. 2008. Growth responses of Ardisia pusilla to the contents of various hydrophilic polymers in the media. Hort. Environ. Biotechnol. 49:365-370.

Still, S.M. 1976. Growth of 'Sunny Mandalay' chrysanthemums in hardwood-bark-amended media affected by insolubilized poly (ethylene oxide). HortScience 11:483-484.

Taylor, A.G., D.E. Klein, and T.H. Whitlow. 1988. SMP: Solid matrix priming of seeds. Sci. Hort. 37:1-11.

Wang, Y.T. 1987. Driving your soil to drink. Greenhouse Manager $6: 115-121$

Wang, Y.T. and L.L. Gregg. 1990. Hydrophilic polymers- Their responses to soil amendments and effect on properties of soilless potting mix. J. Amer. Soc. Hort. Sci. 115:943-948.

Zheng, G.H., R.W. Wilen, A.E. Slinkard, and L.V. Gusta. 1994. Enhancement of canola seed germination and seedling emergence at low temperature by priming. Crop Sci. 34:1589-1593. 